\title{
Interpreting Philosophy of Indians and Netizens in the Eye of Philosophy of Humanities
}

\author{
Dr. Pratap Kumar Dash \\ Associate Professor in English, \\ C.V. Raman Global University, Bhubaneswar \\ pratapkumardash18@yahoo.com
}

\begin{abstract}
Interpreting philosophy of Indians and Netizens in the eye of Philosophy of humanities may sound absurd to many but it seems to have a solid ground since in many ways the former seems to be providing the most convenient ways of daily life but the latter is based on the basic human values which are inseparable from human being because the human being is a product of nature who is completely attributed with feelings, emotions, imaginations, love, relationship, kindness and the like. IT or software philosophers talk of the virtual world, artificial intelligence (AI), ALife, roboethics, ethical hacking and cyber warfare like things and human emotion control though AI, controlling brain through brain-net and giving concepts like digital immortality whereas the basic value of humanities speaks of natural creativity, better sociocultural ambiance, real-world and real-life relations, morality, spirituality and the ultimate search for truth, manual labor and agrarian economy in which such technology can be used for making things smoother but its continuous updating and creating a host of consumers of AI or internet or informatics or absorbed in an undeclared warfare of IT world would not provide many solutions to maintain peace and harmony among the people of the world in the long run. So, keeping the philosophy of humanities a constant, the paper focuses on both positive and negative dimensions of such a flooding move of the human world from real to the virtual and counts on some of the valued opinions of philosophers and poets those who apprehend that it would lead to the loss of true value of human body and mind, and create a host of idiots who are crazy for information and communication and cannot run without the help of such technology-driven gadgets.
\end{abstract}

Keywords: Indians and netizens, philosophy of humanities, AI, robotics, real-life relations, spirituality, virtual world, information, and wisdom
Reference to this paper

should be made as follows:

Received: 15.07.2020

Approved: 28.09.2020

\section{Dr. Pratap Kumar Dash}

Interpreting Philosophy of Indians and Netizens in the Eye of Philosophy of Humanities

Article No. 21

RJPSS Sept. 2020, Vol. XLV No. 2, pp. $181-190$

Online available at: https://anubooks.com/rjpss2020-vol-xlv-no-2/

https://doi.org/10.31995/

rjpss.2020.v45i01.021 
Interpreting Philosophy of Indians and Netizens in the Eye of Philosophy of Humanities Dr. Pratap Kumar Dash

\section{Introduction}

It is worthwhile to say that we learn in our study of the philosophy of humanities that human being is the best machine ever produced by its creator on this planet. Its memory, creativity, innovative capacity, commitment, and tolerance are immense. What's more, all these attributes are embedded with the healing touch of human feelings, empathy, and universality of faith. So, the attempt to interpret the philosophy of informatics, internet, cyber science, AI and IT, ALife, etc. in the eye of the philosophy of humanities sounds logical because the former is younger and not mature enough whereas the latter is as old as the human civilization. Like natural science, human philosophy has helped us open our eyes towards ethical and moral values; distinguish between rational and irrational; clarify the means of obtaining enlightenment and ultimate attainment of wisdom; provide tips to possess active conscience and consciousness; learn to see into the truth of things; help to distinguish between illusion and reality; find the difference between temporal and eternal; enjoy aesthetics of nature and spiritual pleasure; gain knowledge about how to pursue life activities like mystics and rationalists; focus on renunciation. This also helps us comprehend between the cause and effect; reason and emotion; vision and values; freedom of spirit; distinguish between rational and irrational; search for silence in the midst of sounds; finite and infinite assumptions; defining sin and virtue; creativity, intuition and a lot many things with which we have been associated with our philosophical entities of body, mind, society, and culture in day to day life. We have already realized that philosophy deals with the creams of human wisdom with a long-lasting value which is very much the fact of law of nature. The Bible, The Quran, and The Gita or Buddhist philosophy, pantheistic, metaphysical, spiritual, or natural philosophy of the Vedas, Socrates, Aristotle, Isaac Newton, and scores of others have so far acted as our lampposts. Of course, I detest one thing in human philosophy that if it is the words of wisdom, it cannot be categorized as Western or Eastern or the like because it is a grounded theory of truth and an outcome of hundreds of years of observation and analysis of universal truth. So, philosophy is always universal and eternal. Once formulated, it cannot be the intellectual property of an individual or group because it is inherent and invaluable possession of the best of human attributes in harmony with nature internal as well as nature external. Human philosophy acts on commons sense and conscience. It does not only focus on the gross or the substantial existence but also meditates on the subtle and sensitive issues. It should not claim for the patient, global recognition, and continuous financial gain of a country for that. This of course happens with discoveries of science and technology today. 
RJPSS Sept. 2020 Vol. XLV No.2, ISSN: (P)0258-1701 (e)2454-3403 Impact Factor: 7.717

https://doi.org/10.31995/rjpss.2020.v45i01.021

\section{The Reality of the Virtual World with IT and Internet}

After the Second World War, the human world has been fast-changing in its external as well as internal forms. External things such as lifestyle or climate are changing fast and we are looking for suitable alternative modes of survival. Unseen forces such as COVID-19 have brought about a change in the perception of science and redefines social relationships. We are well equipped with so much of knowledge of health and hygiene, nuclear energy, space science, etc. but an unseen virus has created panic in the whole world and we are a cripple. In the meantime, the human being has accepted rapid industrialization which has already made us heavily dependent on machines, power generation, and updating technology leaving its close association with nature. The invention of the computer has brought about a great revolution in spearheading IT, informatics, cyber science, robotics, etc. and its countless different forms. Everything has been computerized turning us to become netizens or digital citizens. Internally, we have been programmed to accumulate lots of information that may be from the fast-changing technical, educational, entertainment, lifestyle, and even many other daily life matters like media designed resources.

In this way, it goes by an impulse that we have been categorized as the creators of computer or information technology known as Indians, and the consumers of their product, as well as technology, are netizens or digital citizens. There are software engineers, IT specialists in the first category, and the Netizensthose who reflect the new non-geographically based social membership.' (Hauben). Now, in addition to etiquette, the netizens are learning netiquette. Every morning, at an average being common people, when we get up, at first we look at the messages in the mailbox, Whatsapp, Facebook, and other electronic media. Then, we respond or reply to those messages. Every day, we remain busy in responding to telephonic calls, watching audios and videos in different electronic modes such as mobile phones, tablets, laptops, and computer or digitized television. Our children and many professionals are busy creating their own virtual worlds such as graphics, animations, pictures, videos, and audios. People make use of programming and software applications to accomplish their works created out of ideas and imaginations. There is already the trend of listening to prayers, slokas and mantras, playing games; watching sex; make cashless transactions, money fraudulence; online trading, online game-playing, home-theatre, online food order, and many more things. This has become the trend of the day because people have no time to do everything physically. Incorporate culture, there is a time-bound target and competitive atmosphere. From time to time, one has to go on innovating new ideas associated with this electronic 
Interpreting Philosophy of Indians and Netizens in the Eye of Philosophy of Humanities

Dr. Pratap Kumar Dash

or IT world or online world and bring it to the market and make it a business. There is plenty of information and communication at our fingertips now. It has provided us so much of knowledge and intellectual freedom that we had never dreamt of before. No government in the world is on par with this revolution. A message hardly takes an hour to reach across the world as people stay connected round the clock. People enjoy posting daily personal updates; shrugging the atlas, we talk to people for hours on video and audio calls. In this way, netizens are the members of the virtual world. Whenever, they feel like, they make use of such a world to entertain their children. Gadgets and software applications have become a common means for education, treatment of health, and many more things including the most devastating war.

Some people constantly misuse this IT or digital platform or cyber technology for which pictures, videos, and information go viral leading to hot debates and comments for some time. People become stars overnight miraculously with likes subscription and sharing of their channels. There are hackers and cyber pirates for whom software experts remain busy in preparing updated cyber-security systems. Since this science has become the dire need of everybody, all the electronic products have become mass products and companies frame a number of policies to trick upon the consumers to buy, use and buy again because, in the very regular gap of time, they update their technology and give new features and some more problemsolving activities so that people feel like throwing the old one and buy a new one. Possessing a new and updated version of an electronic gadget has become a symbol of comfort and status among the people nowadays.

Some netizens have become so ITholic or internetholic that it affects their nervous system. Their muscles, eyes get affected. Spondylitis and mental stress are common among many. Some also develop internet mania which leads to anxiety for which for each and every matter they search in the Google for information. They rely on it more than the knowledge of others and him/her as well. Some risk life for selfie mania or games such as BlueWhale risking life. Robots and Artificial Intelligence has been contributing to the humanity in multiple ways

But its negative side cannot be ignored. People get robots to make their lives easy. However, do they make us lazy? People nowadays hardly do any work involving true manual labor. In the modern context, there is less need for people to move around which has become responsible up to some extent for making us sick with overweight, diabetes, and high blood pressure.

Then, giants in the robotics industry have started building humanoid robots. They are built in a manner to resemble the human body. Creating robots to look and 
RJPSS Sept. 2020 Vol. XLV No.2, ISSN: (P)0258-1701 (e)2454-3403 Impact Factor: 7.717 https://doi.org/10.31995/rjpss.2020.v45i01.021

behave like actual human beings can motivate people to develop emotions towards these machines. This can promote trust within users. Could we depend and be overattached to robots, causing problems when they are not around? An example of this scenario is depicted in the film Her (2013) where a man develops a relationship with an intelligent computer operating system that has been personified through a female voice.

Billions of software engineers throughout the world are always busy developing software; writing syntax; giving codes as commands; trying to replicate the human mind and measuring emotions and creativity using machines. They look for cyberspace. They put life and programmed the brain and make the machine move. This is as dynamic as the presence of soul and brain in a human body and except it cannot give life and growth to it.

\section{IT Philosophy: An Overview}

Here, I would like to focus critically on the views of the modern IT philosophers. They say that one of the great values of modern information technology is that it makes the recording and retrieval of information easy and almost automatic. Today, a growing number of people enter biometric data such as blood pressure, calorie intake, exercise patterns, etc. into applications designed to help them achieve a healthier lifestyle. This type of data collection could become almost fully automated in the near future. Through the use of smartwatches or technologies such as the "Fitbit," or gathered through a user's smartphone, such as applications that use the GPS tracking to track the length and duration of a user's walk or run. How long until a smartphone collects a running data stream of your blood pressure throughout the day perhaps tagged with geolocation markers of particularly high or low readings? In one sense this could be immensely powerful data that could lead to much healthier lifestyle choices.

This conflict in values inculcated by Indians and netizens has been debated by philosophers. The argument of Hauben(1995) in this regard is presented here. He says that while many of the hackers interviewed by Levy argue that hacking is not as dangerous as it seems and that it is mostly about gaining access to hidden knowledge of how information technology systems work, Eugene Spafford counters that no computer break-in is entirely harmless and that the harm precludes the possibility of ethical hacking except in the most extreme cases (Spafford 2007 quoted by Hauben). He continues saying that Kenneth Himma largely agrees that the activity of computer hacking is unprincipled but that politically motivated hacking or "Hacktivism" may have some moral justification, though he is hesitant to give his 
Interpreting Philosophy of Indians and Netizens in the Eye of Philosophy of Humanities

Dr. Pratap Kumar Dash

complete endorsement of the practice due to the largely anonymous nature of the speech necessitated by the hacktivist protests.

Quoting Aristotle it says that humans realize a good and true life through virtuous friendships. Vallor notes that four key dimensions of Aristotle's 'virtuous friendship,' namely: reciprocity, empathy, self-knowledge, and the shared life, and that the first three are found in online social media in ways that can sometimes strengthen friendship (Vallor 2011, 2016). Yet she argues that social media is not yet up to the task of facilitating what Aristotle calls 'the shared life.' Meaning that social media can give us shared activities but not the close intimate friendship that shared daily lives can give. Thus these media cannot fully support the Aristotelian notion of complete and virtuous friendship by themselves (Vallor 2011). Vallor also has a similar analysis of other Aristotelian virtues such as patience, honesty, and empathy, and their problematic application in social media (Vallor 2010). Vallor has gone on to argue that both the users and designers of information technologies need to develop a new virtue that she terms "technomoral wisdom" which can help us foster better online communities and friendships (Vallor, 2016 quoted by Hauben). The question arises as to what extent this technomoral wisdom helps to inculcate the values of patience, honesty, self-restraint, and empathy. In this context, Coeckelbergh goes on to claim that computer games could be designed to facilitate virtues like empathy and cosmopolitan moral development, thus he is not arguing against all games just those where the violence inhibits moral growth (Coeckelbergh 2007 quoted by Hauben).

Its philosophy is still dubious in bringing about a consensus in stopping undeclared round the clock warfare among the Indians across the world. When malware and spyware are created by state actors, we enter the world of informational warfare and a new set of moral concerns. Every country in the world experiences daily cyber-attacks. The majority of these attacks seem to be just probing for weaknesses but they can devastate a countries internet such as the cyber-attacks on Estonia in 2007 and those in Georgia which occurred in 2008. While the Estonian and Georgian attacks were largely designed to obfuscate communication within the target countries more recently informational warfare has been used to facilitate remote sabotage. The famous Stuxnet virus used to attack Iranian nuclear centrifuges is perhaps the first example of weaponized software capable of creating remotely damaging physical facilities. The coming decades will likely see many more cyber weapons deployed by state actors along well-known political fault lines.

Patrick Grim has been a long-time proponent of the idea that philosophy should utilize information technologies to automate and illustrate philosophical 
RJPSS Sept. 2020 Vol. XLV No.2, ISSN: (P)0258-1701 (e)2454-3403 Impact Factor: 7.717 https://doi.org/10.31995/rjpss.2020.v45i01.021

thought experiments (Grim et al. 1998; Grim 2004). Peter Danielson (1998) has also written extensively on this subject beginning with his book Modeling Rationality, Morality, and Evolution with much of the early research in the computational theory of morality centered on using computer models to elucidate the emergence of cooperation between simple software AI or ALife agents (Sullins 2005 quoted in Stanford Encyclopaedia of Philosophy).

\section{Evaluating the Future of Humanity with Indians and Netizens' Philosophy}

Quoting statements from Stanford Encyclopaedia of Philosophy, again we would like to bring in Luciano Florida and J. W. Sanders argument that information, as it is used in the theory of computation, can serve as a powerful idea that can help resolve some of the famous moral conundrums in philosophy such as the nature of evil (1999, 2001). They propose that along with moral evil and natural evil, both concepts familiar to philosophy; we add a third concept they call artificial evil (2001). But one thing sounds quite hypothetical that Indians or Netizens' philosophy is still embedded in experiments, hypothetical assumptions and its future could be indeterminate. The most important thing is how to visualize the human and machine relationship in terms of long-lasting natural, socio-cultural, and higher moral value which includes a larger spectrum of spiritual, creative, and in-depth humanitarian concerns within a permissible economic and anthropomorphic purview. This kind of accumulation, addition, revision, modification of lots of information has to be evaluated if they cope up with long-lasting human value or just getting addicted to many to be users and consumers of the transient miracles of artificial intelligence. Some visionaries like T.S. Eliot(1888-1965) have the following view on this mechanical civilization which needs to be focused. He says:

The endless cycle of idea and action,

Endless invention, endless experiment,

Brings knowledge of motion, but not of stillness;

Knowledge of speech, but not of silence;

Knowledge of words, and ignorance of the Word.

All our knowledge brings us nearer to our ignorance,

All our ignorance brings us nearer to death,

But nearness to death no nearer to GOD.

Where is the Life we have lost in living?

Where is the wisdom we have lost in knowledge?

Where is the knowledge we have lost in information? 
Interpreting Philosophy of Indians and Netizens in the Eye of Philosophy of Humanities

Dr. Pratap Kumar Dash

The cycles of Heaven in twenty centuries

Bring us farther from GOD and nearer to the Dust. The Rock (1934)

The lines by the Nobel laureate poet are quite thought-provoking and supposed to be the conclusive lines for the humanity which is yet to be realized to its fullest extent. The strange thing is that we know the truth and the consequence of an action. We know what is going to happen finally. But still, then, we never act accordingly. We turn to become experimentalists with our immature and temporary actions that we create within 'our world' which is confined to this world and this frame of the perishable corporeal body with temporal and special limitations. The present ideology of Indians does not conform to the philosophy of human values as outlined in The Gita. It is said that:

\section{Isvara Sarva-bhutanam had-dese 'arjuna tisthati}

bhramayan Sarva-Bhutani yantrarudhani Malaya

(Chapter 18: Conclusion-The Perfection of Renunciation, Text 61)

It says that by the order of the Supreme Soul, material nature fashions a particular type of body to a particular type of living entity to work according to his past desires. The living entity is not independent. One should not think himself independent of the Supreme Personality of Godhead. The individual is always under His control. Therefore his duty is to surrender, and that is the injunction of the next verse. Here, my point of view is that do we take enough of care for ourselves to make us stronger in tune with natural and spiritual wisdom to bring balance between what we create and the motion in which we are?

So far as we know, the basic ground of philosophy of humanities is based on the inquiry of truth; of true knowledge based on long-lasting human value; devotion and simplicity; brooding over highest morality and conscience; preach the means of achieving peace, unity and true happiness; bringing balance between physical and spiritual world; to be visionary about our existence with nature and with all its associated organic elements; to believe in the creator with the greatest reverence; the focus on complete surrender of self which is devoid of ego and ignorance; and being the potential part how to continuously take care of this creation; to distinguish between illusion and reality; distinguish between temporariness and permanence; to inculcate the value of aesthetics; distinguish between perishable and imperishable; to speak of ultimate destiny; consciousness leading to superconsciousness, etc.

It is still to be evaluated if our activities of the modern Indian world give way to construct and preserve nature or you do it at the cost of destruction or distortion 
RJPSS Sept. 2020 Vol. XLV No.2, ISSN: (P)0258-1701 (e)2454-3403 Impact Factor: 7.717 https://doi.org/10.31995/rjpss.2020.v45i01.021

of both natures internal and external? Does it create avenues for nurturing the development of mutual faith, love, kindness, compassion, fellow-feeling, good sense, and infuriate no competition or just the opposite? Does it divide people overaccumulation of material knowledge and wealth and therefore put many into confusion and unprivileged?

Here, a couple of arguments worth presenting. Actually, natural philosophy or natural science in the words of Ostwald is that '...is not like a chain which snaps when only a single link proves to be weak. It is like a tree, or, better still, like a forest, in which all sorts of changes or ravages go on without causing the whole to pass out of existence or cease to be active. The relations between the various phenomena, once they become known, continue to exist as indestructible components of all future science.' (Introduction)

\section{Conclusion}

Indians talk of machine morality and robot ethics (roboethics). They formulate methods to deal with virus and system crashes. Artificial Intelligence is going to be the law of the system of controlling our IntelliSense through the introduction of ALife.It will control the brain and emotion. It can relay your feelings in visual forms. Anyhow, the artificial intelligence that we incorporate in the machine is directly proportionate to the loss or dormancy of that intelligence because we start trusting the machine for all that. In terms of humanities, we study about how to bring about harmony between nature internal and nature external. The understanding of life and the surrounding nature is simple and direct just as we see plants and trees, birds and animals, light, fire, and air. It praises the miracle of using manure to make the crops grow better or even if apply filth to a rose plant, it accepts and makes us the beautiful blossoms of rose. It appreciates the inherent feature of artifacts that sustains our body and mind throughout life. In this context, it would be pertinent to say that machines made by a human being cannot bring a miracle for us. They can never motivate intrinsically to accept spiritual philosophy; never give the definition of rational and irrational; no question of wisdom and intuition. They only create a group of consumers of information and communication, entertainment and IT or help netizens' to make money in which almost all have to be skilled as per the changing technology or stay neglected. This becomes a great challenge all over the world to have full IT or net literacy irrespective of the knowledge and opportunities and this leads to a greater generation gap too. Netizens and Indians develop a habit for which there is a constant war of acquisition of technical knowledge and skill that would empower us materially and it seems that it never leaves space in mind, time to think creatively in multiple ways of survival that prevails all around in 
Interpreting Philosophy of Indians and Netizens in the Eye of Philosophy of Humanities

Dr. Pratap Kumar Dash

nature and culture; and it steals freedom. Maybe we have to think of the statement of Einstein in this context that, "I fear the day that technology will surpass our human interaction. The world will have a generation of idiots."

\section{References}

1. Hauben, Michael. 'Netizens: On the history and impact of Usenet and the Internet,' New York and Beppu, November 1995

2. https://journals.uic.edu/ojs/index.php/fm/article/view/606/527

3. 'Information Technology and Moral Values,' in Stanford Encyclopaedia of Philosophy, First Published Tue Jun 12, 2012; substantive revision Fri Nov 9, 2018

4. https://plato.stanford.edu/entries/it-moral-values/

5. Opening Stanza from Choruses from "The Rock" by T.S.Eliot

6. http://www.wisdomportal.com/Technology/TSEliot-TheRock.html

7. Chapter 18: The Gita, Conclusion-The Perfection of Renunciation, Text 61

8. https://asitis.com/18/61.html 